\title{
Cost- Effectiveness of Avatrombopag for the Treatment of Thrombocytopenia in Patients with Chronic Liver Disease
}

This article was published in the following Dove Press journal: ClinicoEconomics and Outcomes Research

\author{
Deirdre Mladsi $\mathbb{D}^{\prime}$ \\ Christine Barnett ${ }^{\prime}$ \\ Kavita Aggarwal (iD) ${ }^{2}$ \\ Michael Vredenburg $\mathbb{B}^{2}$ \\ Douglas Dieterich ${ }^{3}$ \\ Ray Kim (iD) ${ }^{4}$ \\ 'RTI Health Solutions Research, Triangle \\ Park, NC, USA; ${ }^{2}$ Dova Pharmaceuticals, \\ Durham, NC, USA; ${ }^{3}$ Icahn School of \\ Medicine, New York, NY, USA; ${ }^{4}$ School \\ of Medicine, Stanford University, \\ Stanford, CA, USA
}

Background and Aim: Thrombocytopenia is common in people with chronic liver disease, who frequently undergo invasive procedures. To minimize the risk of bleeding, prophylactic platelet transfusions have traditionally been used but carry many risks. The aim of this study was to evaluate the cost-effectiveness of avatrombopag compared with platelet transfusion and lusutrombopag as a treatment for thrombocytopenia in adult patients with chronic liver disease scheduled to undergo a medical procedure.

Methods: A decision-tree model was developed from a US payer perspective to capture acute events observed in phase 3 global randomized controlled clinical trials and, to support exploratory analyses, potential longer-term complications resulting from a major bleed or thromboembolic event. Treatment costs were taken from publicly available data sources. The interventions were evaluated in the overall trial populations and in subpopulations with higher and lower baseline platelet counts. Results were presented as incremental cost per platelet transfusion avoided. One-way and probabilistic sensitivity analyses were conducted. Results: In the overall population, avatrombopag reduced the need for platelet transfusions and produced cost-savings compared with platelet transfusion $(80 \%$ fewer prophylactic platelet transfusions, $\$ 4250$ lower costs) and lusutrombopag (42\% fewer prophylactic platelet transfusions, $\$ 5819$ lower costs). Similar results were seen in both the higher and lower platelet count subpopulations. The one-way and probabilistic sensitivity analyses found that the use of avatrombopag is cost-saving with the incremental cost-effectiveness ratio in quadrant IV (decreased costs, prophylactic platelet transfusions avoided).

Conclusion: The use of avatrombopag is expected to be cost-saving while reducing the need for prophylactic platelet transfusions compared with platelet transfusion and lusutrombopag.

Keywords: liver diseases platelet transfusion, thrombocytopenia, cost-effectiveness

\section{Introduction}

Thrombocytopenia is common in patients with chronic liver disease (CLD) ${ }^{1}$ and is characterized by a deficiency of platelets (ie, $<150 \times 10^{9} / \mathrm{L}$ ) in the circulatory system. ${ }^{2}$ Patients with CLD undergo a variety of interventions that are associated with risk, including treatments for hepatocellular carcinoma and dental extractions in preparation for transplants, as part of their ongoing care. ${ }^{3,4}$ Standard clinical practice for patients with CLD undergoing a procedure has been to correct platelet counts to $>50 \times 10^{9} / \mathrm{L}^{5}$ to reduce the risk of bleeding complications from these surgical procedures. ${ }^{6}$ The increased risk of bleeding complications is often
Correspondence: Deirdre Mladsi RTI Health Solutions Research, Triangle Park, NC 27709-2194

Tel + I $91954 \mid 7094$

Fax + I 91954I 7222

Email dmladsi@rti.org 
managed with preoperative platelet transfusion; ${ }^{6}$ however, this treatment often does not adequately address the therapeutic need and is associated with substantial risk of allergic reactions, reduced efficacy over time, costs, and potential adverse effects. ${ }^{7}$ Given the limitations with current standard of care, there is a need for a safe and costeffective alternative treatment for thrombocytopenia in patients with CLD who are preparing for a procedure.

Oral thrombopoietin receptor agonists present an alternative treatment option that may be more effective while reducing risk to patients. Avatrombopag (Doptelet, Dova Pharmaceuticals, Durham, NC, USA) is a thrombopoietin receptor agonist approved in the United States (US) for the treatment of thrombocytopenia in adults with CLD who are scheduled to undergo a procedure. Avatrombopag, dosed over 5 days is tailored to the baseline platelet count, with patients receiving $40 \mathrm{mg}$ daily for counts $\geq 40 \times 10^{9} / \mathrm{L}$ to $<50 \times 10^{9} / \mathrm{L}$ and $60 \mathrm{mg}$ daily for counts $<40 \times 10^{9} / \mathrm{L}$. Avatrombopag has been shown to significantly increase the percentage of patients not requiring a platelet transfusion prior to the scheduled procedure and decrease the need for a rescue procedure for bleeding during the 7 days following the scheduled procedure. ${ }^{8}$ Additionally, avatrombopag is generally well tolerated in patients with CLD. ${ }^{8,9}$ Lusutrombopag (Mulpleta, Shionogi, Osaka, Japan) is another thrombopoietin receptor agonist approved for this indication. In contrast to avatrombopag, the dose of lusutrombopag ( $3 \mathrm{mg}$ per day) was fixed, irrespective of baseline platelet count. Randomization in Peck-Radosavljevic et al (2019) ${ }^{10}$ was stratified according to baseline platelet counts $\left(<35 \times 10^{9} / \mathrm{L}, \geq 35 \times 10^{9} / \mathrm{L}\right)$. Lusutrombopag has demonstrated efficacy in treating thrombocytopenia in patients with CLD undergoing invasive procedures. ${ }^{10}$

The objective of this analysis was to evaluate, from a third-party US payer perspective, the potential cost-effectiveness of avatrombopag compared with prophylactic platelet transfusion and lusutrombopag as treatments for adult patients with CLD and severe thrombocytopenia (platelet counts $<50 \times 10^{9} / \mathrm{L}$ ) who are scheduled for an invasive procedure.

\section{Methods}

\section{Model Overview}

A decision-tree model was used to describe the possible pertinent outcomes for patients with CLD undergoing treatment for severe thrombocytopenia before a scheduled procedure. In addition to avatrombopag, the model included prophylactic platelet transfusion and lusutrombopag as comparator strategies.

The model structure (Figure 1) captured the following events for each treatment strategy: treatment success (ie, sufficiently high platelet count to proceed with the scheduled procedure with no need for a prophylactic platelet transfusion [assumed to be $0 \%$ for the platelet transfusion strategy]); prophylactic platelet transfusion in the case of lack of treatment success (assumed to be $100 \%$ for platelet transfusion); and periprocedural bleeding event requiring a rescue procedure. Each treatment and model event was associated with a cost of treatment and the expected cost of a thromboembolic event, adjusted by the probability of experiencing the event. If a strategy was successful, the patient underwent the scheduled procedure, resulting in either no complications and no further treatment or a bleeding event that required a rescue procedure. If a prophylactic strategy was unsuccessful, the patient received a platelet transfusion prior to undergoing the scheduled procedure, resulting in either no complications and no further treatment or a bleeding event that required a rescue procedure. If the original prophylactic strategy was unsuccessful, the cost of a platelet transfusion had incorporated costs associated with a possible adverse event to the platelet transfusion, which may have delayed the scheduled procedure and required an additional platelet transfusion. The time horizon for the base-case analysis was the period required to capture the base-case model events. Scenario analysis was conducted to examine the effect of longer-term serious events. The cost-effectiveness analyses were conducted using the most recent estimates of resource use and treatment costs available from published sources. Costs obtained from the literature were inflated to 2018 costs, as applicable. ${ }^{11}$

\section{Model Population}

The base-case cost-effectiveness analysis considered adult patients with CLD and severe thrombocytopenia (platelet count $<50 \times 10^{9} / \mathrm{L}$ ) who were scheduled to undergo a procedure. In addition, the model facilitated analyses in two subpopulations classified in the avatrombopag clinical trials (Table 1): adult patients with a mean baseline platelet count $<40 \times 10^{9} / \mathrm{L}$ (ie, lower platelet count population) and adult patients with a mean baseline platelet count $\geq 40 \times 10^{9} / \mathrm{L}$ to $<50 \times 10^{9} / \mathrm{L}$ (ie, higher platelet count population). The subpopulations in the lusutrombopag clinical 


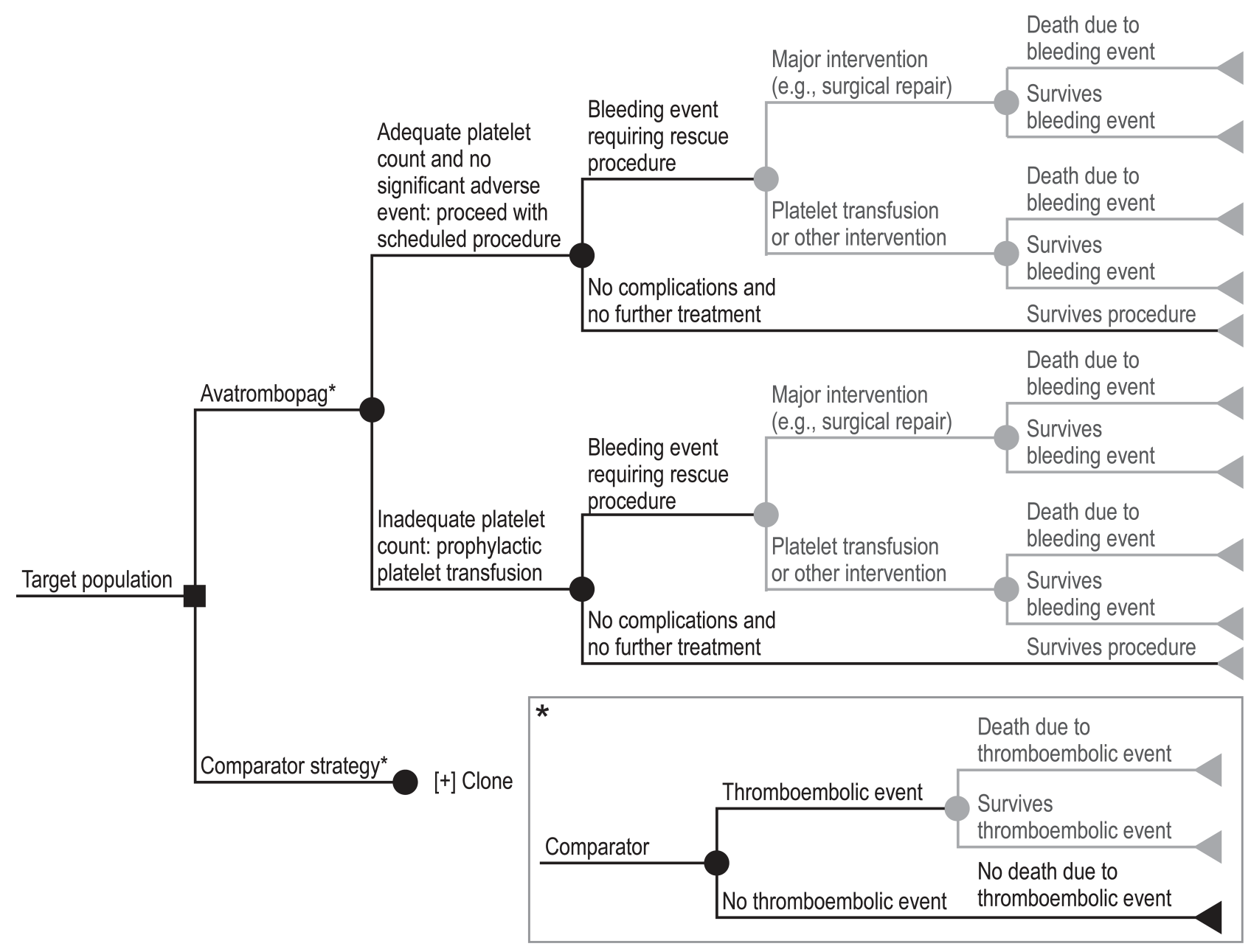

Figure I Cost-effectiveness model structure.

Notes: [+] Clone refers to a copy of the decision-tree branches directly above. Grey portions of the tree denote components that are used only during scenario analyses. *Included in the cost of each treatment is the expected cost of a thromboembolic event.

trials were defined slightly differently, using a cut-point of $35 \times 10^{9} /$ L. Additionally, the avatrombopag and lusutrombopag trials had different proportions in the two subpopulations: $42.3 \%$ of patients in the avatrombopag trials and $64.7 \%$ in the lusutrombopag trials had higher baseline platelet counts.

\section{Model Inputs \\ Event Probabilities}

The probabilities that each drug treatment successfully raised a patient's platelet count, thus avoiding the need for a prophylactic platelet transfusion, were based on the phase 3 multinational clinical trials conducted for avatrombopag and the prescribing information for lusutrombopag (Table S-1) ${ }^{8,12,13}$ Prophylactic transfusions prior to the procedure were needed by $20.3 \%$ of overall avatrombopag patients and $35 \%$ of overall lusutrombopag patients.
For the platelet transfusion model comparator, it was assumed that $100 \%$ of patients received a prophylactic platelet transfusion. Thromboembolic events were experienced by $0.4 \%$ of overall avatrombopag patients and $1.2 \%$ of overall lusutrombopag patients. Based on the pooled placebo arms of the avatrombopag trials, in which $64.7 \%$ of patients received a prophylactic platelet transfusion, the model conservatively assumed that $1.3 \%$ of the patients receiving a prophylactic platelet transfusion experienced a thromboembolic event. Bleeding events requiring a rescue procedure were experienced by $1.1 \%$ of overall avatrombopag patients and $0 \%$ of overall lusutrombopag patients and, based on the avatrombopag placebo arms, were conservatively assumed to be experienced by $4.0 \%$ of patients receiving prophylactic platelet transfusion. Probability estimates of model events for subgroups are presented in Table S-1. 
Table I Population and Subpopulations for Base-Case Analysis

\begin{tabular}{|c|c|c|}
\hline & Parameter Value & Sources and Assumptions \\
\hline Population selected for comparison & $\begin{array}{l}\text { Overall population (all patients with a platelet } \\
\text { count }<50 \times 10^{9} / \mathrm{L} \text { ) }\end{array}$ & \\
\hline \multicolumn{3}{|l|}{ Platelet count cut-point } \\
\hline \multicolumn{3}{|l|}{ Avatrombopag } \\
\hline Lower platelet count population & $<40 \times 10^{9} / \mathrm{L}$ & Doptelet prescribing information $(2018)^{29}$ \\
\hline Higher platelet count population & $\geq 40 \times 10^{9} / \mathrm{L}$ to $<50 \times 10^{9} / \mathrm{L}$ & Doptelet prescribing information $(2018)^{29}$ \\
\hline \multicolumn{3}{|l|}{ Lusutrombopag } \\
\hline Lower platelet count population & $<35 \times 10^{9} / \mathrm{L}$ & Peck-Radosavljevic et al (2019) ${ }^{10}$ \\
\hline Higher platelet count population & $\geq 35 \times 10^{9} / \mathrm{L}$ to $<50 \times 10^{9} / \mathrm{L}$ & Peck-Radosavljevic et al (2019) ${ }^{10}$ \\
\hline $\begin{array}{l}\text { Proportion of population with lower and higher } \\
\text { platelet counts }\end{array}$ & & Doptelet prescribing information $(2018)^{29}$ \\
\hline \multicolumn{3}{|l|}{ Avatrombopag } \\
\hline Lower platelet count population & $57.7 \%$ & Doptelet prescribing information $(2018)^{29}$ \\
\hline Higher platelet count population & $42.3 \%$ & Doptelet prescribing information $(2018)^{29}$ \\
\hline \multicolumn{3}{|l|}{ Lusutrombopag } \\
\hline Lower platelet count population & $35.3 \%$ & AASLD $2017^{\text {al3 }}$ \\
\hline Higher platelet count population & $64.7 \%$ & AASLD $2017^{\mathrm{a} 13}$ \\
\hline
\end{tabular}

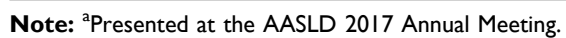

Abbreviation: AASLD, American Association for the Study of Liver Diseases.

\section{Cost Inputs}

\section{Cost of Drug Treatments}

All costs are from a US payer perspective. The treatment costs for the dosages for each drug regimen considered in the model were obtained as wholesale acquisition costs from Red Book Online (2019) ${ }^{14}$ and are presented in Table 2. Drug costs per scheduled procedure were $\$ 3827$ for the overall avatrombopag population, $\$ 2970$ for the higher platelet count avatrombopag population, $\$ 4455$ for the lower platelet count avatrombopag population, and $\$ 8500$ for all lusutrombopag populations.

\section{Cost of Platelet Transfusions}

The direct cost of platelet transfusion in a patient with CLD was based on Barnett et al (2018), ${ }^{7}$ which included the cost of platelet collection, the platelet transfusion event, adverse events from transfusion, and the need for subsequent platelet transfusions in the case of refractoriness with human leukocyte antigen-matched platelets in case of immune refractoriness. The cost of a platelet transfusion as a treatment strategy in this modeled analysis depended on the number of apheresis-equivalent platelet units per platelet transfusion, which varied by population. Based on data from the placebo arm of the avatrombopag trials, the cost of platelet transfusion as a treatment strategy was $\$ 9271$ for the overall platelet transfusion population, $\$ 8564$ for the higher platelet count platelet transfusion population, and $\$ 9790$ for the lower platelet count population.

Table 2 Model Inputs: Treatment Costs per Procedure for Avatrombopag and Lusutrombopag (2019 USD)

\begin{tabular}{|c|c|c|c|c|}
\hline & $\begin{array}{l}\text { Avatrombopag } \\
(40 \mathrm{mg})\end{array}$ & $\begin{array}{l}\text { Avatrombopag } \\
(60 \mathrm{mg})\end{array}$ & $\begin{array}{l}\text { Lusutrombopag } \\
\text { (3 mg) }\end{array}$ & Source Notes \\
\hline $\begin{array}{l}\text { Dose per package/scheduled } \\
\text { procedure }(\mathrm{mg}) \\
\text { WAC per package/scheduled } \\
\text { procedure }\end{array}$ & $\begin{array}{l}200 \\
\$ 2970\end{array}$ & $\begin{array}{l}300 \\
\$ 4455\end{array}$ & $\begin{array}{l}21 \\
\$ 8500\end{array}$ & $\begin{array}{l}\text { Doptelet prescribing information }(2018) ;^{29} \\
\text { Mulpleta prescribing information }(2018)^{12} \\
\text { Red Book Online }(2019)^{14}\end{array}$ \\
\hline $\begin{array}{l}\text { Weighted average WAC per } \\
\text { package/scheduled procedure } \\
\text { for avatrombopag }\end{array}$ & $\$ 3827$ & & Not applicable & $\begin{array}{l}\text { Calculated the weighted average cost of } \\
\text { avatrombopag per scheduled procedure based } \\
\text { on the distribution by subpopulation }\end{array}$ \\
\hline
\end{tabular}

Abbreviations: USD, US dollar; WAC, wholesale acquisition cost. 
Some patients receiving the drug treatments also received platelet transfusions, the cost of which depended on the number of apheresis-equivalent units of platelets, which varied by drug and population. The cost of a prophylactic platelet transfusion was $\$ 7253$ for the overall avatrombopag population. The number of apheresisequivalent platelet units per platelet transfusion for lusutrombopag was unavailable from the published literature; it was assumed to be the same as for avatrombopag, yielding the same cost for platelet transfusion (\$7253). The number of apheresis-equivalent platelet units per platelet transfusion for all populations are provided in Table S-2.

\section{Cost of Adverse Events}

\section{Thromboembolic Event}

In a retrospective case-control study comparing the cost of hospitalization for US patients with a diagnosis of CLD and venous thromboembolism (VTE) compared with patients with CLD without VTE from October 2006 to July 2010, Walsh et al (2013) ${ }^{15}$ reported that patients with CLD and VTE had significantly more costly hospitalizations (median $\$ 20,137$ vs $\$ 8450, P=0.03$ ). We assumed that a patient with CLD who experiences a thromboembolic event has an additional cost of $\$ 11,687$ based on this information, which we assumed to be in 2008 US dollars (the middle of the study period). This estimate was updated to 2018 US dollars to be $\$ 15,344$.

\section{Rescue Procedure for Bleeding}

Ineffective treatment for thrombocytopenia prior to a procedure may lead to a periprocedural bleeding event that may require a rescue procedure. Our model assumed that the rescue procedure for bleeding is a platelet transfusion. The cost of a platelet transfusion was derived from Barnett et al $(2018)^{7}$ assuming no refractoriness and no delay in procedure following a major adverse event, resulting in an estimate of $\$ 4745$.

\section{Sensitivity Analysis Inputs}

One-way sensitivity analyses were conducted to estimate the effects of parameter uncertainty on the incremental cost per prophylactic platelet transfusion avoided (the incremental cost-effectiveness ratio [ICER] most relevant to understanding the economic value of the treatment). One-way sensitivity analyses compared avatrombopag with prophylactic platelet transfusion or lusutrombopag in the overall population. Probabilistic sensitivity analyses were conducted to compare the ICER of avatrombopag with prophylactic platelet transfusion or lusutrombopag in the overall population. Reported values from the literature or assumptions were used to support the one-way and probabilistic sensitivity analyses (Table S-3).

\section{Long-Term Outcomes Scenario Design and Inputs}

Long-term outcomes were considered using a scenario analysis. Longer-term health outcomes were discounted by $3 \%{ }^{16}$ Table $\mathrm{S}-4$ presents the additional model parameters required to perform the scenario analysis incorporating long-term outcomes. To estimate the cost of a surgical repair for bleeding, the 2013 Healthcare Cost and Utilization Project's National Inpatient Sample, a publicly available database, ${ }^{17}$ was analyzed to estimate the mean cost (adjusted to 2017 US dollars) of a hospitalization for patients with a primary discharge diagnosis of a gastrointestinal bleed (International Classification of Diseases, $9^{\text {th }}$ Revision, Clinical Modification [ICD-9CM] Diagnoses Codes: 530.82, 569.3, 578.0, or 578.9) who had an intestinal surgical procedure (International Classification of Diseases, $9^{\text {th }}$ Revision [ICD-9] Procedure Codes: 46.71, 46.73, 46.75, 46.79) during the hospitalization. This 2017 estimate was updated to 2018 US dollars. ${ }^{11}$

\section{Results}

\section{Base-Case Results}

The use of avatrombopag in the overall population (Table 3) resulted in an average per-person cost-savings of $\$ 4250$ (44\% reduction) compared with prophylactic platelet transfusion and $\$ 5819$ (52\% reduction) compared with lusutrombopag. Avatrombopag also reduced prophylactic platelet transfusions by $80 \%$ compared with a strategy where $100 \%$ of patients received a prophylactic platelet transfusion and by $42 \%$ compared with lusutrombopag. In the subgroup analyses for higher and lower platelet count groups, the findings from the overall analysis were replicated. In patients with higher platelet counts (Table S-5), avatrombopag reduced costs by $60 \%$ and prophylactic transfusions by $92 \%$ compared with the prophylactic transfusion strategy. Avatrombopag reduced costs by $64 \%$ and prophylactic transfusions by $64 \%$ compared with lusutrombopag. In the lower platelet group (Table S-6), avatrombopag reduced costs by $33 \%$ and prophylactic transfusions by $71 \%$ compared with the prophylactic transfusion strategy. Avatrombopag reduced costs by $48 \%$ and prophylactic transfusions by $49 \%$ compared with lusutrombopag. In an analysis based strictly on 
Table 3 Base-Case Results: Overall Population (Platelet Count $<50 \times 10^{9} / \mathrm{L}$ )

\begin{tabular}{|c|c|c|c|}
\hline Outcome & Avatrombopag & $\begin{array}{l}\text { Prophylactic Platelet } \\
\text { Transfusion }\end{array}$ & Lusutrombopag \\
\hline \multicolumn{4}{|l|}{ Economic outcomes (per person) } \\
\hline Costs of drug treatment & $\$ 3827$ & $\$ 0$ & $\$ 8500$ \\
\hline Costs of prophylactic platelet transfusion & $\$ 1475$ & $\$ 9271$ & $\$ 2552$ \\
\hline Costs of thromboembolic events & $\$ 56$ & $\$ 200$ & $\$ 179$ \\
\hline Costs of bleeding events requiring rescue procedure & $\$ 54$ & $\$ 191$ & $\$ 0$ \\
\hline Total costs & $\$ 5412$ & $\$ 9662$ & $\$ 11,231$ \\
\hline \multicolumn{4}{|l|}{ Health outcomes (per person) } \\
\hline Number of prophylactic platelet transfusions & 0.2034 & 1.0000 & 0.3519 \\
\hline Number of thromboembolic events & 0.0037 & 0.0130 & 0.0117 \\
\hline Number of bleeding events requiring rescue procedure & 0.0113 & 0.0403 & 0.0000 \\
\hline Incremental outcomes (per person) & & $\begin{array}{l}\text { Avatrombopag vs prophylactic } \\
\text { platelet transfusion }\end{array}$ & $\begin{array}{l}\text { Avatrombopag vs } \\
\text { lusutrombopag }\end{array}$ \\
\hline Incremental costs & & $-\$ 4250$ & $-\$ 5819$ \\
\hline Number of prophylactic platelet transfusions avoided & & 0.7966 & 0.1485 \\
\hline Cost per prophylactic platelet transfusion avoided & & $-\$ 5335^{\mathrm{a}}$ & $-\$ 39199^{a}$ \\
\hline
\end{tabular}

Note: a Avatrombopag compared with both prophylactic platelet transfusion and lusutrombopag resulted in lower costs and fewer prophylactic platelet transfusions, yielding a negative cost per prophylactic platelet transfusion avoided, which suggests that avatrombopag is the dominant treatment.

the avatrombopag clinical trials (detailed results not shown here), in the overall population, avatrombopag reduced costs by $15 \%$ and transfusions by $69 \%$ compared with placebo.

\section{Sensitivity Analysis Results One-Way Sensitivity Analysis Results}

One-way sensitivity analyses comparing avatrombopag with prophylactic platelet transfusion and lusutrombopag in the overall population were performed (Figure 2A and B). The analyses found that the use of avatrombopag remained cost-saving, ie, the ICER moved to quadrant IV (decreased costs, prophylactic platelet transfusions avoided), over a wide range of values for the input variables. The use of avatrombopag remained cost-saving in both the higher and lower platelet count subpopulations. The three variables that had the greatest effect on the cost per prophylactic platelet transfusion avoided for avatrombopag versus prophylactic platelet transfusion were (1) cost of prophylactic platelet transfusion for patients treated with prophylactic platelet transfusion, (2) cost of prophylactic platelet transfusion for patients treated with avatrombopag, and (3) prophylactic platelet transfusion probability of thromboembolic event. The three variables that had the greatest effect on the cost per prophylactic platelet transfusion avoided for avatrombopag versus lusutrombopag were (1) probability of inadequate platelet count for procedure for patients receiving lusutrombopag, (2) probability of inadequate platelet count for procedure for patients receiving avatrombopag, and (3) cost of prophylactic platelet transfusion for patients treated with lusutrombopag.

\section{Probabilistic Sensitivity Analysis Results}

A probabilistic sensitivity analysis on the ICER of avatrombopag in comparison with prophylactic platelet transfusion in the overall population was performed (Figure 3A). In total, $99.3 \%$ of the 10,000 iterations had results in quadrant IV, and the remaining percentage $(0.7 \%)$ were in quadrant I (increased costs and decreased number of prophylactic platelet transfusions). A probabilistic sensitivity analysis on the ICER for avatrombopag in comparison with lusutrombopag in the overall population was performed (Figure 3B). In total, $98.9 \%$ of the 10,000 iterations had results in quadrant IV, and the remaining percentage $(1.1 \%)$ was in quadrant III (decreased costs and increased number of prophylactic platelet transfusions).

\section{Long-Term Outcomes Scenario}

Avatrombopag maximized expected life-years, while prophylactic platelet transfusion resulted in the lowest number of expected life-years. The incremental average per-person increase in life-years due to avatrombopag compared with 
A

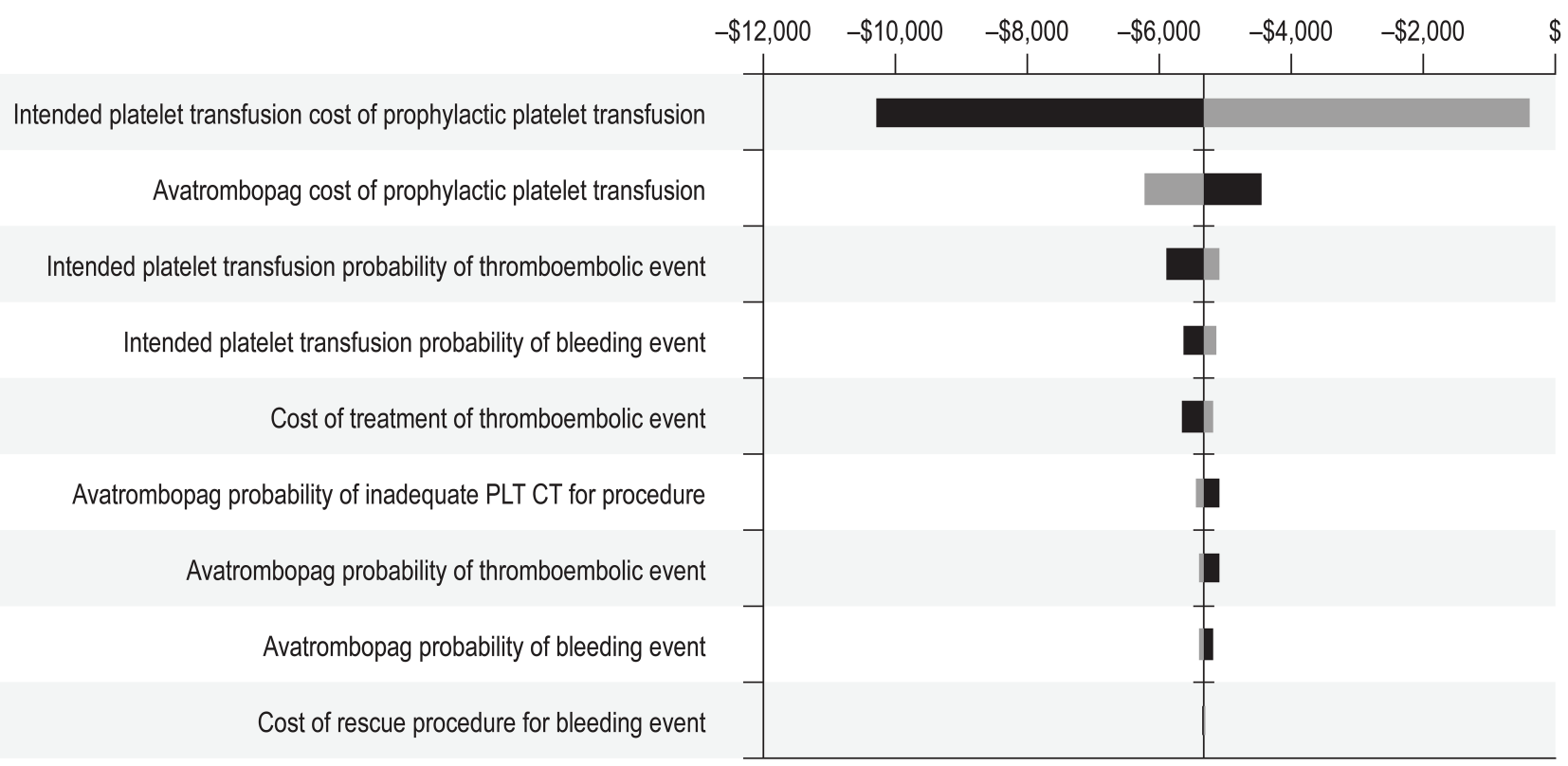

B
Cost per prophylactic platelet transfusions avoided

Cost per prophylactic platelet transfusions avoided

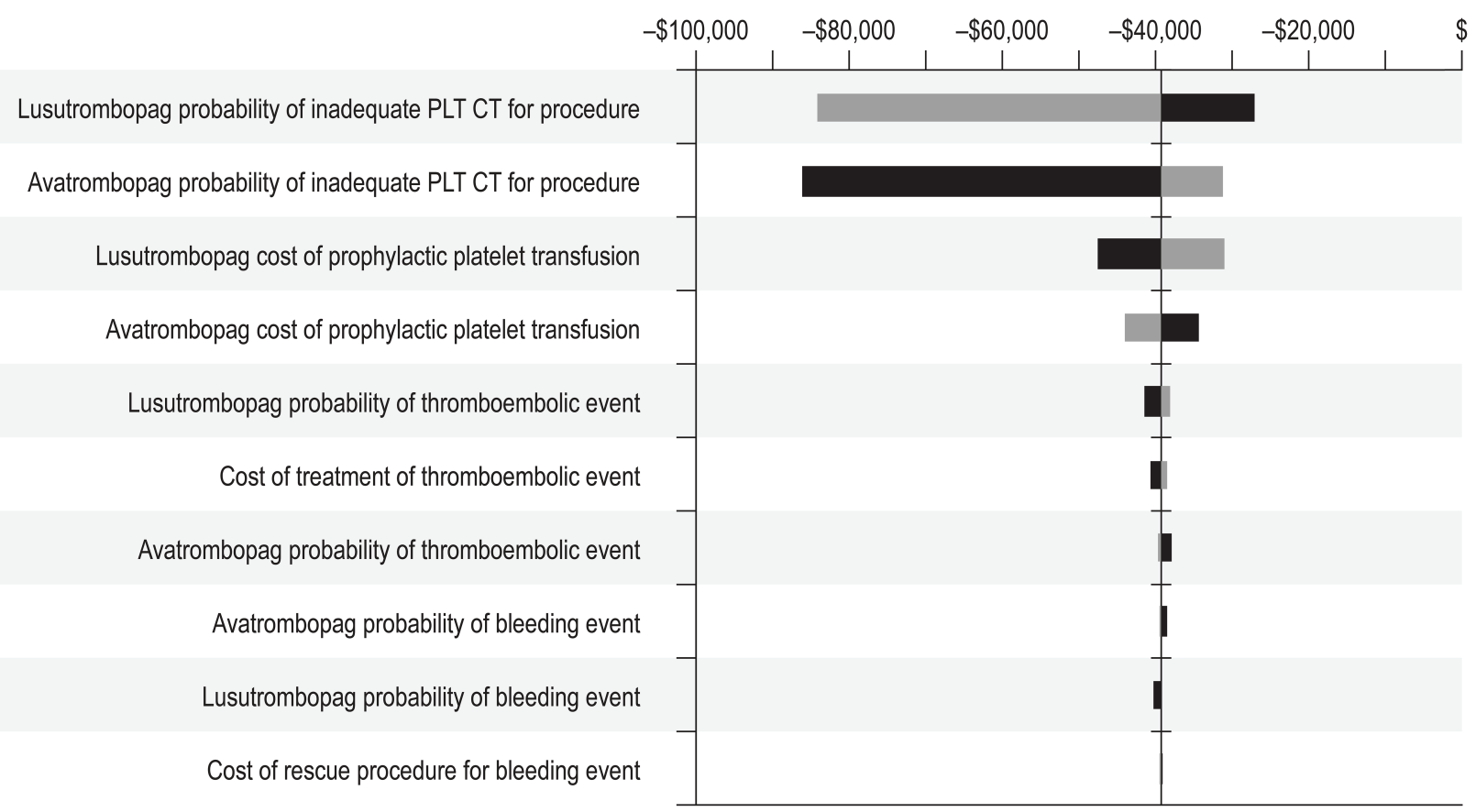

Figure 2 One-way sensitivity analyses results. (A) Cost per prophylactic platelet transfusion avoided with avatrombopag in comparison with prophylactic platelet transfusion in the overall patient population. (B) One-way sensitivity analysis results: cost per prophylactic platelet transfusion avoided with avatrombopag in comparison with lusutrombopag in the overall population.

Note: Gray indicates the lower bound and black indicates the upper bound.

prophylactic platelet transfusion (0.0076 additional undiscounted life-years and 0.0036 additional discounted lifeyears) (Table 4) was not significant due to the low probability of a major event with long-term costs and negative health outcomes. In the long-term scenario analysis, the use of avatrombopag remained cost-saving across all scenarios, including in both the higher and lower platelet count subpopulations (Tables S-7 and S-8). 


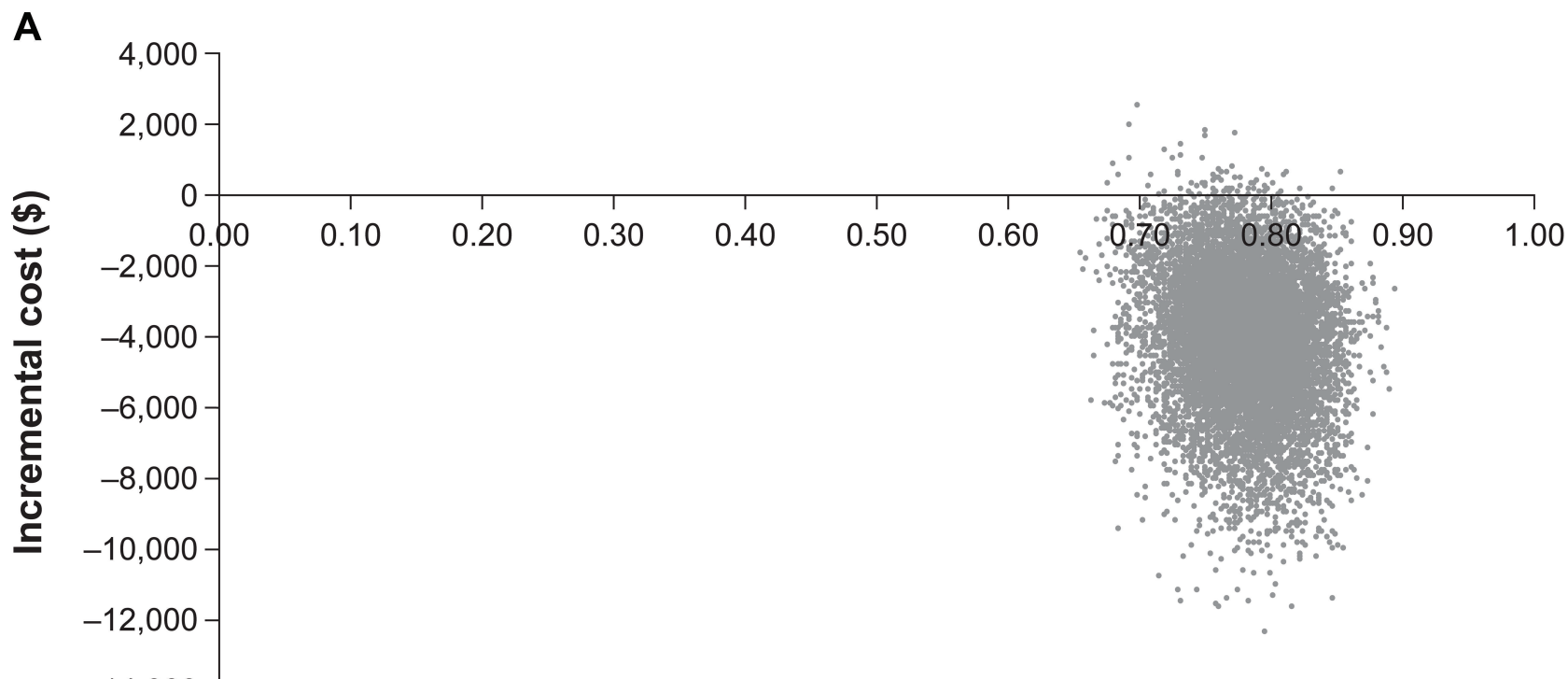

$-14,000$ Prophylactic platelet transfusions avoided

B

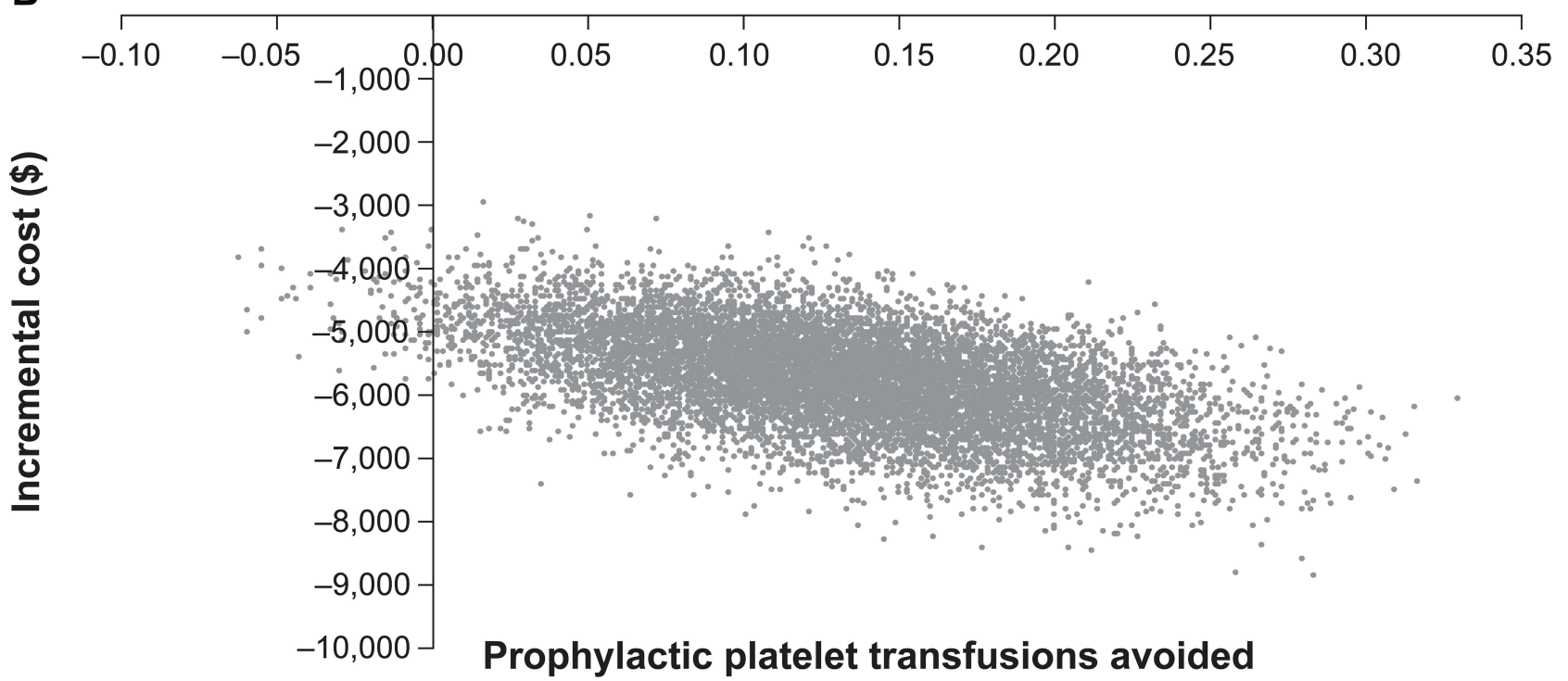

Figure 3 Probabilistic sensitivity analyses results. (A) Probabilistic sensitivity analysis results: cost per prophylactic platelet transfusion avoided with avatrombopag in comparison with prophylactic platelet transfusion in the overall population. (B) Probabilistic sensitivity analysis results: cost per prophylactic platelet transfusion avoided with avatrombopag in comparison with lusutrombopag in the overall population.

\section{Discussion}

The main finding in this study is that the use of avatrombopag reduces health care costs compared with prophylactic platelet transfusion and lusutrombopag while decreasing the number of prophylactic platelet transfusions required regardless of treatment strategy. In the base-case, one-way sensitivity, and probabilistic sensitivity analyses, avatrombopag compared favorably to prophylactic platelet transfusion and lusutrombopag in the overall population as well as in both the higher and lower platelet count subpopulations. Avatrombopag continued to be the most costeffective treatment option in the long-term outcomes scenario for the overall population and subpopulations, as well as in a strictly trial-based analysis comparing avatrombopag with placebo.

In the one-way sensitivity analysis comparing avatrombopag with prophylactic platelet transfusion, two of the three variables with the greatest impact on the results were 
Table 4 Base-Case Results for Scenario Analysis Incorporating Long-Term Outcomes: Overall Population (Platelet Count $\left.<50 \times 10^{9} / \mathrm{L}\right)$

\begin{tabular}{|c|c|c|c|}
\hline Outcome & Avatrombopag & Prophylactic Platelet Transfusion & Lusutrombopag \\
\hline \multicolumn{4}{|l|}{ Economic outcomes (per person) } \\
\hline Costs of treatment & $\$ 3827$ & $\$ 0$ & $\$ 8500$ \\
\hline Costs of prophylactic platelet transfusion & $\$ 1475$ & $\$ 9271$ & $\$ 2552$ \\
\hline Costs of thromboembolic events & $\$ 56$ & $\$ 200$ & $\$ 179$ \\
\hline Costs of bleeding events requiring surgical repair & $\$ 19$ & $\$ 68$ & $\$ 0$ \\
\hline $\begin{array}{l}\text { Costs of bleeding events requiring other rescue } \\
\text { procedure }\end{array}$ & $\$ 52$ & $\$ 185$ & $\$ 0$ \\
\hline Total costs & $\$ 5429$ & $\$ 9724$ & $\$ 11,231$ \\
\hline \multicolumn{4}{|l|}{ Health outcomes (per person) } \\
\hline Number of prophylactic platelet transfusions & 0.2034 & 1.0000 & 0.3519 \\
\hline Number of thromboembolic events & 0.0037 & 0.0130 & 0.0117 \\
\hline Number of bleeding events requiring surgical repair & 0.0004 & 0.0014 & 0.0000 \\
\hline $\begin{array}{l}\text { Number of bleeding events requiring other rescue } \\
\text { procedure }\end{array}$ & 0.0109 & 0.0389 & 0.0000 \\
\hline Number of life-years (undiscounted) & 24.2619 & 24.2543 & 24.2585 \\
\hline Number of life-years (discounted) & 18.0606 & 18.0570 & 18.0590 \\
\hline Incremental outcomes & & $\begin{array}{l}\text { Avatrombopag vs prophylactic platelet } \\
\text { transfusion }\end{array}$ & $\begin{array}{l}\text { Avatrombopag vs } \\
\text { lusutrombopag }\end{array}$ \\
\hline Incremental costs & & $-\$ 4294$ & $-\$ 5802$ \\
\hline $\begin{array}{l}\text { Number of prophylactic platelet transfusions } \\
\text { avoided }\end{array}$ & & 0.7966 & 0.1485 \\
\hline Incremental life-years (undiscounted) & & 0.0076 & 0.0034 \\
\hline Incremental life-years (discounted) & & 0.0036 & 0.0016 \\
\hline Cost per prophylactic platelet transfusion avoided & & $-\$ 5391^{a}$ & $-\$ 39,084^{a}$ \\
\hline
\end{tabular}

Note: ${ }^{a}$ Avatrombopag compared with both prophylactic platelet transfusion and lusutrombopag resulted in lower costs and fewer prophylactic platelet transfusions, yielding a negative cost per prophylactic platelet transfusion avoided, which suggests that avatrombopag is the dominant treatment.

related to the cost of prophylactic platelet transfusion (\$9662). Additionally, the cost of platelet transfusion ${ }^{7}$ depends on the risk of adverse events. However, the risks of adverse events are not well understood in this patient population. ${ }^{18}$ If adverse event risks are significantly higher in this patient population than those in the overall group of patients who may receive a platelet transfusion, the cost of platelet transfusions may increase, which could change the cost-effectiveness analysis results.

Thrombocytopenia can cause the delay or cancellation of procedures in patients with CLD. ${ }^{6}$ In CLD patients, even procedures considered routine in other populations, such as dental extraction, can carry a risk of bleeding due to thrombocytopenia. ${ }^{4,19}$ Although prophylactic platelet transfusion can be recommended to increase platelet count prior to conducting a procedure, ${ }^{5,20}$ platelet transfusions may not be effective in preventing bleeding. Consequently, transfusion continues to impose a substantial economic burden on health care systems. ${ }^{21,22} \mathrm{~A}$ recent retrospective study of claims data found a mean payment increase of $\$ 11,100(25 \%)$ in total costs for patients with
CLD and thrombocytopenia who received platelet transfusions during a planned invasive procedure-related hospital admission and matched patients who did not receive transfusion. ${ }^{23}$ The increased cost of platelet transfusions was attributed to increased resource utilization and lengths of hospital stay driven by a significant increase in bleeding events and acute respiratory failure. A 2013 AABB survey ${ }^{24}$ reported 54 hospitals (10.5\% of those surveyed) delayed elective surgeries due to unmet platelet needs, demonstrating that reliance on platelet transfusion can cause the postponement of procedures. Platelet transfusions also can present additional burdens to patients through decreased quality of life and increased time away from work. ${ }^{25}$ We found that avatrombopag provides an effective option to reduce both the cost and risk to patients with CLD and thrombocytopenia prior to undergoing a planned procedure.

While lusutrombopag reduced risk to patients compared with prophylactic platelet transfusion, the use of lusutrombopag was associated with a 16\% (\$1569) increased cost for the overall population. Although the 
increased expense may be partly explained by the difference in cost of drug, efficacy differences at lower baseline platelet count with lusutrombopag may also be a factor. Lusutrombopag is dosed only as a single strength regardless of platelet count, whereas avatrombopag dosing is tailored based on baseline platelet count.

This analysis has been completed for the US; however, the burden of disease may be greater in other regions, in particular lower-income countries, where the prevalence of $\mathrm{HCV}$ is higher. ${ }^{26}$ Non-communicable diseases also impose an increasing burden on developing nations. ${ }^{27}$ Additional research on the cost-effectiveness of treating non-communicable diseases, including thrombocytopenia in patients with CLD, is needed to generate health economic evaluations applicable to lower and middle-income countries. ${ }^{28}$

This cost-effectiveness analysis has several limitations. It is important to note the lack of head-to-head data comparing avatrombopag with lusutrombopag. The base-case parameters used an unadjusted comparison with lusutrombopag, which may make it difficult to make a robust estimate of comparative effectiveness. Additionally, the base-case analysis assumed that lusutrombopag and avatrombopag required equivalent platelet units per prophylactic platelet transfusion following drug treatment, resulting in the same cost per prophylactic platelet transfusion. Additionally, because of the nature of conducting registration-directed clinical trials, there is a lack of data on less-common, longer-term outcomes. Therefore, the base-case modeled analysis focused on short-term outcomes observed in clinical trials (eg, platelet transfusions to elevate platelet count, rescue procedures for bleeding). The results of the one-way sensitivity analysis suggest that further research into the full cost of platelet transfusion could affect the findings from this analysis. Although Barnett et al (2018) ${ }^{7}$ detailed the cost of a platelet transfusion in the US, there is a lack of information crucial to understanding the full cost of a platelet transfusion, as the authors noted data gaps in the literature. Since not all costs could be accounted for in the cost estimate from that study, the platelet transfusion cost used here may be an underestimate. Finally, the trial-based outcomes need to be validated in a real-world setting. For example, the risk of bleeding may be higher in a real-world than in a trial setting.

\section{Conclusion}

Patients with CLD and thrombocytopenia often have their platelet counts increased to reduce the risk of bleeding before undergoing a variety of procedures. The introduction of the thrombopoietin receptor agonists, avatrombopag and lusutrombopag, can reduce the use of platelet transfusions and decrease the associated patient burdens and risks. The administration of avatrombopag has shown to be cost-saving compared with prophylactic platelet transfusion and lusutrombopag, while also reducing the risk of thromboembolic events or bleeding events requiring rescue procedures in this patient population.

\section{Abbreviations}

CLD, Chronic liver disease; ICER, Incremental cost-effectiveness ratio; US, United States; VTE, venous thromboembolism.

\section{Acknowledgments}

The authors thank Brian Samsell and Kate Lothman of RTI Health Solutions for providing medical writing assistance. The abstract of this paper was presented at the $62^{\text {nd }}$ American Society of Hematology (ASH) Annual Meeting and Exposition as a poster presentation with interim findings. The poster's abstract was published as a supplement in Blood: https://doi.org/10.1182/blood-2019-131822.

\section{Author Contributions}

All authors made a significant contribution to the work reported, whether that is in the conception, study design, execution, acquisition of data, analysis and interpretation, or in all these areas; took part in drafting, revising or critically reviewing the article; gave final approval of the version to be published; have agreed on the journal to which the article has been submitted; and agree to be accountable for all aspects of the work.

\section{Funding}

RTI Health Solutions (Research Triangle Park, NC, USA), an independent nonprofit research organization that does work for government agencies and pharmaceutical companies, received funding under a research contract with Dova Pharmaceuticals (Durham, NC, USA) to conduct this study and provide editorial support in the form of manuscript writing, styling, and submission.

\section{Disclosure}

DM and CB are employees of RTI Health Solutions, Research Triangle Park, NC, USA, which received funding under a research contract with Dova Pharmaceuticals, Durham, NC, USA, to conduct this study. MV is an 
employee of Dova Pharmaceuticals. KA was an employee of Dova Pharmaceuticals during the study period. RK has received honoraria for consulting and participating in advisory boards for Dova. DD has received honoraria for participating in advisory boards for Dova. All relevant conflict of interests have been reported for each author. The authors report no other conflicts of interest in this work.

\section{References}

1. Giannini EG. Review article: thrombocytopenia in chronic liver disease and pharmacologic treatment options. Aliment Pharmacol Ther. 2006;23:1055-1065. doi:10.1111/j.1365-2036.2006.02889.x

2. Smock KJ, Perkins SL. Thrombocytopenia: an update. Int $J$ Lab Hematol. 2014;36:269-278. doi:10.1111/ijlh.12214

3. Kurokawa T, Ohkohchi N. Platelets in liver disease, cancer and regeneration. World J Gastroenterol. 2017;23:3228-3239. doi:10.37 48/wjg.v23.i18.3228

4. Cocero N, Bezzi M, Martini S, et al. Oral surgical treatment of patients with chronic liver disease: assessments of bleeding and its relationship with thrombocytopenia and blood coagulation parameters. J Oral Maxillofac Surg. 2017;75:28-34. doi:10.1016/j.joms.2016.08.033

5. Patel IJ, Rahim S, Davidson JC, et al. Society of Interventional Radiology consensus guidelines for the periprocedural management of thrombotic and bleeding risk in patients undergoing percutaneous image-guided interventions-Part II: recommendations: endorsed by the Canadian Association for Interventional Radiology and the Cardiovascular and Interventional Radiological Society of Europe. $J$ Vasc Interv Radiol. 2019;30:1168-1184 e1161. doi:10.1016/j.jvir.20 19.04.017

6. Poordad F. Review article: thrombocytopenia in chronic liver disease. Aliment Pharmacol Ther. 2007;26:5-11. doi:10.1111/j.1365-2036.20 07.03510.x

7. Barnett CL, Mladsi D, Vredenburg M, et al. Cost estimate of platelet transfusion in the United States for patients with chronic liver disease and associated thrombocytopenia undergoing elective procedures. $J$ Med Econ. 2018;21(8):827-834. doi:10.1080/13696998.2018.1490301

8. Terrault N, Chen YC, Izumi N, et al. Avatrombopag before procedures reduces need for platelet transfusion in patients with chronic liver disease and thrombocytopenia. Gastroenterology. 2018;15 5:705-718. doi:10.1053/j.gastro.2018.05.025

9. Terrault NA, Hassanein T, Howell CD, et al. Phase II study of avatrombopag in thrombocytopenic patients with cirrhosis undergoing an elective procedure. $J$ Hepatol. 2014;61:1253-1259. doi:10. 1016/j.jhep.2014.07.007

10. Peck-Radosavljevic M, Simon K, Iacobellis A, et al. Lusutrombopag for the treatment of thrombocytopenia in patients with chronic Liver Disease Undergoing Invasive Procedures (L-PLUS 2). Hepatology. 2019;70:1336-1348. doi:10.1002/hep.30561

11. BLS [Bureau of Labor Statistics]. Inflation \& prices: medical care services in U.S. city average, all urban consumers, not seasonally adjusted. 2018. Available from: https://www.bls.gov/data/. Accessed May 2, 2018.

12. Mulpleta prescribing information. Mulpleta (Lusutrombopag). Florham Park, NJ: Shionogi Inc; 2018. Available from: https:// www.accessdata.fda.gov/drugsatfda_docs/label/2018/210923s000lbl. pdf. Accessed September 7, 2018.

13. Afdhal NH Lusutrombopag for Treatment of Thrombocytopenia in Patients Undergoing Non-Emergency Invasive Procedures: Results from An International Phase 3, Randomized, Double-Blind, Placebo-Controlled Study (L-PLUS 2). Presented at the American Association of the Study of Liver Diseases Annual Meeting; 2017. Washington, DC.
14. Red Book Online. Ann Arbor, MI. Truven Health Analytics; 2019. Available from: http://www.micromedexsolutions.com. Accessed June 20, 2019.

15. Walsh KA, Lewis DA, Clifford TM, et al. Risk factors for venous thromboembolism in patients with chronic liver disease. Ann Pharmacother. 2013;47:333-339. doi:10.1345/aph.1R496

16. Sanders GD, Neumann PJ, Basu A, et al. Recommendations for conduct, methodological practices, and reporting of cost-effectiveness analyses: second panel on cost-effectiveness in health and medicine. JAMA. 2016;316:1093-1103. doi:10.1001/jama.2016.12195

17. HCUP NIS Database Documentation. Healthcare Cost and Utilization Project (HCUP). 2019. Available from: https://www.hcup-us.ahrq. gov/db/nation/nis/nisdbdocumentation.jsp. Accessed July 21, 2020.

18. Mladsi DM, Barnett CL, Kaye JA. Psy2 - identification of potential bias from data sources and study designs used to estimate platelet transfusion adverse event rates. Value in Health. 2018;21:S436. doi:10.1016/j.jval.2018.09.2579

19. Helenius-Hietala J, Åberg F, Meurman JH, et al. Oral surgery in liver transplant candidates: a retrospective study on delayed bleeding and other complications. Oral Surg Oral Med Oral Pathol Oral Radiol. 2016;121:490-495. doi:10.1016/j.oooo.2016.01.025

20. Rockey DC, Caldwell SH, Goodman ZD, et al. Liver biopsy. Hepatology. 2009;49:1017-1044. doi:10.1002/hep.22742

21. Fontaine MJ, Chung YT, Rogers WM, et al. Improving platelet supply chains through collaborations between blood centers and transfusion services. Transfusion. 2009;49:2040-2047. doi:10.1111/ j.1537-2995.2009.02236.x

22. Toner RW, Pizzi L, Leas B, et al. Costs to hospitals of acquiring and processing blood in the US: a survey of hospital-based blood banks and transfusion services. Appl Health Econ Health Policy. 2011;9:29-37. doi:10.2165/11530740-000000000-00000

23. Brown RS, Bentley R, Cai B, et al. The clinical and economic burden of patients with chronic liver disease and thrombocytopaenia receiving platelet transfusions during planned invasive procedures. GastroHep. 2019;1:236-248. doi:10.1002/ygh2.357

24. Whitaker B, Rajbhandary S, Kleinman S, et al. Trends in United States blood collection and transfusion: results from the 2013 AABB blood collection, utilization, and patient blood management survey. Transfusion. 2016;56:2173-2183. doi:10.1111/trf.13676

25. Brown RS Jr. Review article: a pharmacoeconomic analysis of thrombocytopenia in chronic liver disease. Aliment Pharmacol Ther. 2007;26:41-48. doi:10.1111/j.1365-2036.2007.03505.x

26. Mohd Hanafiah K, Groeger J, Flaxman AD, et al. Global epidemiology of hepatitis $\mathrm{C}$ virus infection: new estimates of age-specific antibody to HCV seroprevalence. Hepatology. 2013;57:1333-1342. doi:10.1002/hep.26141

27. Jakovljevic M, Jakab M, Gerdtham U, et al. Comparative financing analysis and political economy of noncommunicable diseases. $J$ Med Econ. 2019;22:722-727. doi:10.1080/13696998.2019.1600523

28. Jakovljevic M, Matter-Walstra K, Sugahara T, et al. Cost-effectiveness and resource allocation (CERA) 18 years of evolution: maturity of adulthood and promise beyond tomorrow. Cost Eff Resour Alloc. 2020;18:15. doi:10.1186/s12962-020-00210-2

29. Doptelet prescribing information. DOPTELET (Avatrombopag). Durham, NC: Dova Pharmaceuticals, Inc.; 2018.

30. Straube S, Tramer MR, Moore RA, et al. Mortality with upper gastrointestinal bleeding and perforation: effects of time and NSAID use. BMC Gastroenterol. 2009;9:41. doi:10.1186/1471230X-9-41

31. Stepanova M, Clement S, Wong R, et al. Patients with diabetes and chronic liver disease are at increased risk for overall mortality: a population study from the United States. Clin Diabetes. 2017;35:7983. doi: $10.2337 / \mathrm{cd} 16-0018$

32. Fineberg SJ, Oglesby M, Patel AA, et al. The incidence and mortality of thromboembolic events in lumbar spine surgery. Spine (Phila Pa). 1976;2013(38):1154-1159. 


\section{Publish your work in this journal}

ClinicoEconomics and Outcomes Research is an international, peerreviewed open-access journal focusing on Health Technology Assessment, Pharmacoeconomics and Outcomes Research in the areas of diagnosis, medical devices, and clinical, surgical and pharmacological intervention. The economic impact of health policy and health systems organization also constitute important areas of coverage. The manuscript management system is completely online and includes a very quick and fair peer-review system, which is all easy to use. Visit http://www.dovepress.com/testimonials.php to read real quotes from published authors.

Submit your manuscript here: https://www.dovepress.com/clinicoeconomics-and-outcomes-research-journal 